\title{
Minireviews
}

\section{The Influence of Nicotine on Lung Tumor Growth, Cancer Chemotherapy, and Chemotherapy-Induced Peripheral Neuropathy}

\author{
S. Lauren Kyte and David A. Gewirtz \\ Department of Pharmacology and Toxicology (S.L.K., D.A.G.) and Massey Cancer Center (D.A.G.), Virginia Commonwealth \\ University, Richmond, Virginia
}

Received March 26, 2018; accepted May 30, 2018

\begin{abstract}
Studies in animal models have suggested that nicotine, an agonist of nicotinic acetylcholine receptors, may have the potential to prevent and/or reverse the peripheral neuropathy induced by cancer chemotherapeutic drugs, such as paclitaxel and oxaliplatin. However, a large body of evidence suggests that nicotine may also stimulate lung tumor growth and/or interfere with the effectiveness of cancer chemotherapy. Whereas the reported proliferative effects of nicotine are highly variable, the antagonism of antitumor drug efficacy is more consistent, although this latter effect has been demonstrated primarily in cell culture studies. In contrast, in vitro and in vivo studies from our own laboratory
\end{abstract}

indicate that nicotine fails to enhance the growth of nonsmall cell lung cancer cells or attenuate the effects of chemotherapy (paclitaxel). Given the inconsistencies in the literature, coupled with our own findings, the weight of evidence suggests that caution may be warranted in proposing to use nicotine to mitigate chemotherapy-induced peripheral neuropathy in cancer patients receiving chemotherapy. Conversely, clinical trials could be performed in patients who have completed therapy and are considered to be disease-free to determine whether nicotine, in the form of commercially available patches or gum, is effective in alleviating peripheral neuropathy symptoms.

\section{Introduction}

Nicotine Action in the Nervous System and in Tumor Cells. Nicotine is an agonist of the nicotinic acetylcholine receptors (nAChRs), which are pentameric ligand-gated ion channels located on the membranes of various cells in the nervous and immune systems, as well as in lung tumor cells. These receptors can be homomeric, with five subunits of the same type $(\alpha 7, \alpha 9)$, or heteromeric, with a combination of both $\alpha$ and $\beta$ subunits (including $\alpha 1-7, \alpha 9-10$, and $\beta 1-4$ ). Binding of an agonist such as nicotine to a nAChR induces a conformational change that allows for the influx of sodium and calcium ions. In neurons, this ion flux results in depolarization of the cell and initiation of an action potential. In tumor cells, both calcium-dependent and calcium-independent downstream signaling pathways of nAChRs appear to be activated; stimulation of these signaling pathways has been reported to contribute to proliferative and antiapoptotic actions of nicotine [see reviews

This work was supported by the National Institutes of Health [Grant 1R01CA206028-01 (to M.I.D. and D.A.G.) and Grants T32 DA007027-41 and 1F31CA224993-01 (to S.L.K.)] and, in part, by a Massey Cancer Center Pilot Project Grant (to D.A.G. and M.I.D.)

https://doi.org/10.1124/jpet.118.249359. by Egleton et al. (2008), Improgo et al. (2011), Schaal and Chellappan (2014), and Czyżykowski et al. (2016)].

Antinociceptive and Analgesic Actions of Nicotine. Both human and animal studies have demonstrated that nicotine possesses analgesic and antinociceptive properties, respectively. For example, randomized placebo-controlled clinical trials have revealed that nicotine can reduce postoperative pain scores in nonsmokers, as well as decrease morphine consumption (Flood and Daniel, 2004; Habib et al., 2008). In rats, Di Cesare Mannelli et al. (2013) demonstrated that acute administration of nicotine can reverse trauma-induced neuropathic pain as well as oxaliplatin-induced cold and mechanical allodynia, both of which are characteristic of chemotherapy-induced peripheral neuropathy (CIPN). Our laboratory, in collaboration with the Damaj group, has also shown that nicotine can both prevent and reverse paclitaxel-induced mechanical allodynia in mice following chronic and acute administration, respectively (Kyte et al., 2018). These two reports are, to our knowledge, currently the only publications investigating the use of nicotine in CIPN animal models, indicating that there is a need to explore the antiallodynic property of nicotine with other classes of cancer chemotherapy drugs that cause CIPN, such as the vinca alkaloids and bortezomib. 
The Potential Utility of Nicotine for Mitigation of Chemotherapy-Induced Peripheral Neuropathy. Further investigation of the promising actions of nicotine in suppressing the development of and/or reversing the symptoms of CIPN could be compromised by the extensive body of literature, largely focused on lung cancer, which suggests nicotine can either promote tumor growth and/or reduce the antitumor effects of cancer chemotherapy. If these properties of nicotine translate to the clinic, then its use may be limited to patients who have previously undergone cancer therapy and are currently considered to be disease-free, because CIPN symptoms can persist for over 6 months after cancer chemotherapy administration has been completed (Seretny et al., 2014). Therefore, even patients with cancer in complete remission may still be experiencing neuropathic pain and could benefit from nicotine treatment. If, however, nicotine could also be administered in combination with chemotherapy to prevent the development of CIPN in cancer patients, this would potentially provide an even greater patient benefit.

In our recent publication establishing the antinociceptive actions of nicotine in a mouse model of paclitaxel-induced peripheral neuropathy (Kyte et al., 2018), we also reported that nicotine does not stimulate proliferation of nonsmall cell lung cancer (NSCLC) or ovarian cancer cells in vitro, nor enhance NSCLC tumor growth in vivo. This work also demonstrated that nicotine fails to interfere with the antiproliferative and cytotoxic actions of paclitaxel in NSCLC cells in culture, whereas our recent unpublished studies have reproduced these findings in tumor-bearing mice (manuscript in preparation). These observations are in conflict with a large body of evidence that argues against the use of nicotine within the framework of tumor growth or the utilization of cancer chemotherapy [see reviews by Catassi et al. (2008) and Grando (2014)]. More specifically, nicotine has been shown to be capable of promoting tumor cell proliferation, invasion and metastasis, angiogenesis, and resistance to apoptotic cell death via various signaling pathways. To evaluate the potential utilization of nicotine for the alleviation of CIPN symptoms in cancer patients and/or cancer survivors, this review will summarize the previous literature that investigates the effects of nicotine on lung cancer progression both alone and in combination with antitumor drugs. It should be emphasized that this review is not addressing the potential roles of nicotine and nAChRs in carcinogenesis [see reviews by Dang et al. (2016) and Haussmann and Fariss (2016)], but rather focuses on the interaction of nicotine with established tumors and its impact on the antitumor properties of cancer chemotherapy.

\section{Studies in Cell Culture}

Nicotine Alone. Approximately half of the publications relating to nicotine and lung cancer in vitro have reported significant increases in various assays assessing lung cancer cell progression (Tables 2 and 3); the lung cancer type for each cell line used in these studies is indicated in Table 1. However, the experimental systems used are not uniform. Almost half of the in vitro experiments were conducted under conditions of serum deprivation or serum starvation with the purpose of eliminating exogenous growth factors and/or inducing quiescence to synchronize the cell cycle. This approach creates an environment where enhanced proliferation induced by nicotine is likely to be more pronounced (Rosner et al., 2013); however, the physiologic relevance may be limited. The majority of serum starvation/deprivation studies show an increase in lung tumor cell viability (viable cell number), proliferation, growth, invasion, and/or migration following nicotine exposure over a wide range of nicotine concentrations ( $10 \mathrm{nM}$ to $500 \mu \mathrm{M}$; Table 3). In contrast, a number of studies reported no effects of nicotine ( $1 \mathrm{pM}$ to $100 \mu \mathrm{M}$ for $48-72$ hours) on lung cancer cell viability, growth, or proliferation even under the relatively nonphysiologic condition of serum deprivation (Heeschen et al., 2001; Jarzynka et al., 2006; Mucchietto et al., 2017). In our own studies, nicotine exposure ( $1 \mu \mathrm{M}$ for 24 hours) under either serum deprivation or serum starvation conditions had essentially no influence on NSCLC cell viability (Kyte et al., 2018).

If the administration of nicotine via nicotine patches or gum could prove to have utility for the prevention or treatment of CIPN, then it is necessary to evaluate the previous literature within the framework of plasma nicotine concentrations in patients using nicotine replacement therapy (NRT). Nicotine patches $(21 \mathrm{mg})$ deliver peak plasma concentrations of $18-23 \mathrm{ng} / \mathrm{ml}$ or $111-142 \mathrm{nM}$ nicotine within 8 hours of use, after which the levels gradually decline until the patch is removed at 24 hours postapplication (Fant et al., 2000); 2-4 mg nicotine gum provides maximum nicotine concentrations of $6-17 \mathrm{ng} / \mathrm{ml}$ or $37-105 \mathrm{nM}$ after 30 minutes of chewing (Benowitz et al., 1987). Although e-cigarettes are unlikely to be considered for therapeutic use, these devices can generate circulating nicotine concentrations of $7-25 \mathrm{ng} / \mathrm{ml}$ or $43-154 \mathrm{nM}$ (Wagener et al., 2017). These values suggest that concentrations of nicotine in cell culture studies between 35 and $200 \mathrm{nM}$ would encompass the range of plasma nicotine levels that

TABLE 1

Lung cancer cell lines grouped by species and lung cancer type

The cell lines indicated as primary were derived from human lung cancer tissue samples and not purchased commercially.

\begin{tabular}{clc}
\hline Species & \multicolumn{1}{c}{ Lung Cancer Type } & Lung Cancer Cell Lines \\
\hline \multirow{2}{*}{ Human } & Nonsmall cell lung cancer & A549, H23, H157, H358, H460, H1299, H1703, H1975, H5800, PC9, 11-18 \\
& Small cell lung cancer & DMS-53, H446, N417, N592 \\
& Adenocarcinoma & HCC827, T1 (primary), 201T (primary) \\
& Bronchoalveolar carcinoma & H1650 \\
& Papillary adenocarcinoma & H4411 \\
& Squamous cell carcinoma & SW900 \\
Mouse & Lewis lung carcinoma & LLC \\
& Adenocarcinoma & LKR, Line1 \\
\hline
\end{tabular}


would be achieved in patients using NRT. However, the majority of studies have tested nicotine concentrations from $100 \mathrm{nM}$ to $1 \mu \mathrm{M}$, a range that is comparable to or slightly higher than the plasma nicotine levels of $20-60 \mathrm{ng} / \mathrm{ml}$ or 100-400 nM observed after tobacco cigarette smoking (Benowitz et al., 2009). Overall, the studies shown in Table 2 demonstrate the capacity of nicotine to increase lung cancer cell viability, growth, proliferation, invasion, migration, and/or angiogenesis following 30-minute to 2-week exposure to $0.1-1 \mu \mathrm{M}$ nicotine. However, only half of these publications demonstrate significant increases in characteristics of tumor growth, ranging from a $20 \%$ to a $750 \%$ increase, whereas half of the studies do not demonstrate significant enhancement. When considering nicotine levels achieved during NRT use

TABLE 2

In vitro effects of nicotine on lung cancer

\begin{tabular}{|c|c|c|c|c|c|c|}
\hline $\begin{array}{l}\text { Lung Cancer } \\
\text { Cell Line }\end{array}$ & $\underset{(\mu \mathrm{M})}{\text { Nicotine }}$ & $\begin{array}{l}\text { Duration } \\
\text { of Treatment }\end{array}$ & $\begin{array}{c}\text { Serum } \\
\text { Concentration }\end{array}$ & $\begin{array}{l}\text { Cellular Response } \\
\text { (Assay) }\end{array}$ & Result (Relative to Control) & Reference \\
\hline $\begin{array}{l}14 \text { SCLC and } \\
\text { NSCLC lines }\end{array}$ & $0.1-1$ & 5 days & $10 \%$ & Viability (MTT) & No effect & $\begin{array}{l}\text { Maneckjee and Minna } \\
\text { (1990) }\end{array}$ \\
\hline H460, H157 & $0.1-1$ & 7 days & $10 \%$ & Viability (MTT) & No effect & Chen et al. (2002) \\
\hline $201 \mathrm{~T}$ & 1 & $48 \mathrm{~h}$ & $10 \%$ & Viability (MTS) & No effect & Carlisle et al. (2007) \\
\hline $\mathrm{H} 460$ & $0.1,1$ & 5 days & $10 \%$ & $\begin{array}{l}\text { Viability } \\
\text { (Cell Titer-Glo) }\end{array}$ & $20 \%, 25 \%$ increase $*$ & Zheng et al. 2007) \\
\hline \multirow[t]{2}{*}{ A549 } & 1 & $24 \mathrm{~h}$ & $10 \%$ & Viability (MTT) & $20 \%$ increase* & Zhang et al. (2009) \\
\hline & & & & $\begin{array}{l}\text { Growth }\left(\left[{ }^{3} \mathrm{H}\right]-\right. \\
\text { thymidine })\end{array}$ & $50 \%$ increase* & \\
\hline \multirow[t]{3}{*}{ A549, H1299 } & $0.1,1$ & $72 \mathrm{~h}$ & Not indicated & Viability (MTT) & $\begin{array}{l}\text { H1299: } 20 \%, 5 \% \text { increase }^{\dagger} \\
\text { A549: } 10 \%, 15 \% \text { increase }\end{array}$ & $\begin{array}{l}\text { Puliyappadamba } \\
\text { et al. (2010) }\end{array}$ \\
\hline & & $72 \mathrm{~h}$ & & $\begin{array}{l}\text { Growth }\left(\left[{ }^{3} \mathrm{H}\right]-\right. \\
\text { thymidine })\end{array}$ & $\begin{array}{l}\text { H1299: } 15 \%, 5 \% \text { increase }^{\dagger} \\
\text { A549: } 20 \%, 10 \% \text { increase }^{\dagger}\end{array}$ & \\
\hline & & $\begin{array}{l}\text { Previously treated } \\
\text { for } 72 \mathrm{~h} \text {, then } \\
\text { seeded }\end{array}$ & & $\begin{array}{l}\text { Proliferation (colony } \\
\quad \text { formation) }\end{array}$ & A549: $175 \%$ increase $(1 \mu \mathrm{M})^{\dagger}$ & \\
\hline H441, H1299 & 1 & 30 min or 7 day $^{a}$ & $10 \%$ & Viability (MTT) & $\begin{array}{l}100 \%, 75 \% \text { increase }(30 \mathrm{~min}))^{*} \\
375 \%, 250 \% \text { increase }(7 \text { days })^{*}\end{array}$ & Al-Wadei et al. (2012) \\
\hline H446 & $0.1-1$ & $12-72 \mathrm{~h}$ & $10 \%$ & Viability (MTT) & $\begin{array}{l}8,5 \% \text { increase at } 12 \mathrm{~h}(0.1,0.25 \mu \mathrm{M}),^{\dagger} \\
\text { no effect at } 24-48 \mathrm{~h}, \\
8 \% \text { decrease at } 72 \mathrm{~h} \\
(0.5,1 \mu \mathrm{M})^{\dagger}\end{array}$ & Zeng et al. (2012) \\
\hline A549 & 1 & $\begin{array}{l}3-5 \text { days } \\
24 \mathrm{~h}\end{array}$ & $10 \%$ & $\begin{array}{l}\text { Viability (MTT) } \\
\text { Invasion (Boyden) }\end{array}$ & $\begin{array}{l}40 \%-80 \% \text { increase } \\
60 \% \text { increase* }\end{array}$ & Wu et al. (2013) \\
\hline A549 & $0.1,1$ & $24 \mathrm{~h}$ & $10 \%$ & Viability (MTS) & $40 \%, 55 \%$ decrease $*$ & Gao et al. (2016) \\
\hline LKR, H5800 & 1 & $2 \mathrm{wk}^{b}$ & $10 \%$ & $\begin{array}{l}\text { Proliferation } \\
\quad \text { (colony formation) }\end{array}$ & $13 \%, 24 \%$ increase $^{\dagger}$ & Nishioka et al. (2010) \\
\hline SW900 & 1 & $24 \mathrm{~h}$ & Not indicated & $\begin{array}{l}\text { Proliferation } \\
\quad \text { (cell counting) }\end{array}$ & $275 \%$ increase* & $\begin{array}{l}\text { Chernyavsky et al. } \\
\text { (2015) }\end{array}$ \\
\hline \multirow[t]{2}{*}{ A549 } & 1 & $24 \mathrm{~h}$ & $10 \%$ & Invasion (Transwell) & $7 \%$ increase & Sun and Ma (2015) \\
\hline & & 8 or $24 \mathrm{~h}$ & & $\begin{array}{l}\text { Migration (wound } \\
\text { healing) }\end{array}$ & $\begin{array}{l}10 \% \text { increase }(8 \mathrm{~h}), \\
28 \% \text { increase }(24 \mathrm{~h}) *\end{array}$ & \\
\hline $\begin{array}{l}\text { A549, H460, } \\
\text { LLC, T1 }\end{array}$ & $0.1-1$ & $24 \mathrm{~h}$ & $10 \%$ & $\begin{array}{l}\text { Viability } \\
\text { (MTS, MTT) }\end{array}$ & No effect & Kyte et al. (2018) \\
\hline \multirow[t]{3}{*}{ A549, H460 } & 1 & $48-96 \mathrm{~h}$ & & $\begin{array}{l}\text { Viability } \\
\text { (MTS, MTT) }\end{array}$ & No effect & \\
\hline & 1 & $48 \mathrm{~h}$ & & $\begin{array}{l}\text { Proliferation } \\
\quad \text { (cell counting) }\end{array}$ & No effect & \\
\hline & 1 & $24 \mathrm{~h}$ & & $\begin{array}{l}\text { Proliferation (colony } \\
\text { formation) }\end{array}$ & No effect & \\
\hline \multirow[t]{2}{*}{ A549 } & $0.5,1$ & $16 \mathrm{~h}$ & $10 \%$ & $\begin{array}{l}\text { Angiogenesis } \\
(\mathrm{HIF}-1 \alpha)\end{array}$ & $350 \%, 750 \%$ increase $*$ & Zhang et al. (2007) \\
\hline & & & & $\begin{array}{l}\text { Angiogenesis } \\
\text { (VEGF) }\end{array}$ & $\begin{array}{l}14 \% \text { increase }(0.5 \mu \mathrm{M}) \\
43 \% \text { increase }(1 \mu \mathrm{M})^{*}\end{array}$ & \\
\hline $\begin{array}{l}\text { A549, H1299, } \\
\text { H1975 }\end{array}$ & $0.1,1$ & $24 \mathrm{~h}$ & $10 \%$ & Viability (MTT) & $\begin{array}{l}\text { A549: } 39,52 \% \text { increase* } \\
\text { H1299: } 13 \% \text { increase } \\
(0.1 \mu \mathrm{M}), \\
20 \% \text { increase }(1 \mu \mathrm{M})^{*} \\
\text { H1975: 30\% increase } \\
(0.1 \mu \mathrm{M}), \\
52 \% \text { increase }(1 \mu \mathrm{M})^{*}\end{array}$ & Ma et al. (2014) \\
\hline A549 & $0.1-1$ & $16 \mathrm{~h}$ & & $\begin{array}{l}\text { Angiogenesis } \\
\quad(\mathrm{HIF}-1 \alpha)\end{array}$ & $\begin{array}{l}20 \%-40 \% \text { increase } \\
\quad(0.1,0.5 \mu \mathrm{M}) \\
\quad 100 \% \text { increase }(1 \mu \mathrm{M})^{*}\end{array}$ & \\
\hline A549 & $0.1-1$ & $16 \mathrm{~h}$ & & $\begin{array}{l}\text { Angiogenesis } \\
\text { (VEGF) }\end{array}$ & $\begin{array}{l}75 \%, 125 \% \text { increase } \\
(0.1,0.5 \mu \mathrm{M}) \\
\quad 175 \% \text { increase }(1 \mu \mathrm{M})^{*}\end{array}$ & \\
\hline
\end{tabular}

HIF-1 $\alpha$, hypoxia-inducible factor 1- $\alpha$; LLC, Lewis lung carcinoma; MTS, (3-(4,5-dimethylthiazol-2-yl)-5-(3-carboxymethoxyphenyl)-2-(4-sulfophenyl)-2H-tetrazolium); MTT,

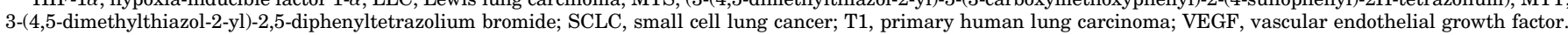
${ }^{a}$ Nicotine was replaced every $24 \mathrm{~h}$.

${ }^{b}$ Nicotine was replenished every 4 days.

*Statistically significant.

${ }^{\dagger}$ Statistical significance not indicated. 
(35-200 nM), only a third of the studies report significant increases in lung cancer cell viability, proliferation, migration, and/or invasion, with approximately half of these experiments having been performed under conditions of serum deprivation or serum starvation (Tables 2 and 3 ). When excluding studies performed under serum deprivation/ starvation conditions and limiting our analysis to the lower, therapeutically relevant concentrations of nicotine, it may be surmised that the effects of nicotine on lung tumor progression with nicotine patch or gum use are likely to be negligible.

In contrast, approximately $40 \%$ of publications testing 0.1-1 $\mu \mathrm{M}$ nicotine under full serum conditions report no effects or modest, nonsignificant effects of nicotine on tumor cell viability, growth, and/or proliferation following 12 hours to 2 weeks of nicotine exposure (Table 2). In addition, studies using nicotine concentrations between $100 \mathrm{nM}$ and $1 \mu \mathrm{M}$ for 24-72 hours under full serum conditions (Zeng et al., 2012; Gao et al., 2016) have reported that nicotine decreases lung tumor cell viability and growth; these reports also showed decreases in lung cancer cell viability with $2.5-15 \mu \mathrm{M}$ nicotine. However, the impact of nicotine at higher nonphysiologic and nonpharmacological concentrations is likely the result of off-target effects and general toxicity; ultrastructural analysis of A549 NSCLC cells treated with $10 \mu \mathrm{M}$ nicotine revealed shrunken nuclei, an increase in both nucleoli and lysosomes, swollen mitochondria, and changes in endoplasmic reticulum morphology after 24 hours (Gao et al., 2016).

Nicotine in Combination with Cancer Chemotherapy. Nearly three quarters of cell culture studies assessing the influence of nicotine on sensitivity to chemotherapy in lung cancer cells show significant interference with chemotherapy (Tables 4 and 5). A nicotine-induced resistance to chemotherapy (average of 50\% decrease in apoptosis with $1 \mu \mathrm{M}$ nicotine) has been observed with annexin $\mathrm{V}$-propidium iodide staining, caspase activity, and DNA fragmentation assays (enzyme-linked immunosorbent assay and cell cycle analysis for sub-G1 population), as well as standard viability assays (Table 4). Lung cancer cells exposed to both cancer chemotherapy and nicotine over the range of $0.1-1 \mu \mathrm{M}$ have been shown to exhibit increased viability and decreased apoptosis, although statistical significance was only reported for about two-thirds of these studies. In contrast, our findings that nicotine ( $1 \mu \mathrm{M}$ for $24-48$ hours with $10 \%$ serum) does not attenuate paclitaxel-induced growth arrest or apoptosis (Kyte et al., 2018) are consistent with studies by other laboratories that have shown a lack of significant effects of nicotine (0.1-1 $\mu \mathrm{M}$ for 1 hour to 1 week with $10 \%$ serum) on cisplatininduced DNA fragmentation (apoptosis) and decreased viability, or on gefitinib-induced decreases in lung cancer cell viability (Carlisle et al., 2007; Nishioka et al., 2010; Zeng et al., 2012; Togashi et al., 2015). Nevertheless, it is apparent that antiapoptotic and prosurvival effects can occur as the concentration of nicotine increases (Table 5). Surprisingly, only one study has been conducted with nicotine in the NRT range, in this case $100 \mathrm{nM}$ nicotine, in combination with chemotherapy (Zeng et al., 2012). This report demonstrated that $100 \mathrm{nM}$ nicotine induces only a modest increase in viability in the presence of $10 \mu \mathrm{M}$ cisplatin and has no effect on cisplatin-induced apoptosis.

\section{Studies in Tumor-Bearing Animals}

As with the cell culture work, studies regarding the effects of nicotine on lung tumor growth and sensitivity to cancer chemotherapy drugs in tumor-bearing animals vary greatly in their design, given the use of both human and murine lung tumor xenografts, carcinogen-induced tumor development, and oncogene-induced spontaneous tumor formation. Excluding studies of nicotine-exposed lung cancer cell xenografts, where the cells were treated with nicotine ex vivo before implantation, approximately two-thirds of the publications show that chronic nicotine administration can significantly increase lung tumor incidence/recurrence, size, weight, and/or metastasis, as well as $\mathrm{Ki}-67$ and angiogenic factor expression in vivo (Table 6). One study included the use of $14 \mathrm{mg}$ NicoDerm CQ patches that were cut to represent $0.45 \mathrm{mg}$ or $25 \mathrm{mg} / \mathrm{kg}$ nicotine (Davis et al., 2009). These transdermal patches were applied to the lower dorsal region of female immunocompetent tumor-bearing mice daily for 2 weeks during tumor growth. Cotinine, a predominant metabolite of nicotine, was quantified in the urine of these mice $(5000 \mathrm{ng} / \mathrm{ml})$ and was shown to be comparable with urine cotinine concentrations in human smokers (1500-8000 ng/ml). Although this animal model well represents cancer patients receiving NRT, the dose of nicotine appears to be higher than what would be expected clinically since nonpregnant women receiving nicotine via a $22 \mathrm{mg}$ patch have been reported to produce $2240 \mathrm{ng}$ cotinine in their urine (Ogburn et al., 1999). In addition, the remaining third of the literature has shown that chronic nicotine administration does not enhance lung tumor incidence, multiplicity, volume, and/or growth $\left(\mathrm{Ki}-67^{+}\right.$population) in mice (Pratesi et al., 1996; Maier et al., 2011; Murphy et al., 2011), as also reported in our own studies (Kyte et al., 2018).

Surprisingly, to our knowledge, only one study has been published involving systemic coadministration of nicotine and cancer chemotherapy in vivo. Li et al. (2015) observed significant increases in PC9 human lung adenocarcinoma tumor volume in BALB/c nude mice following administration of erlotinib ( $100 \mathrm{mg} / \mathrm{kg}$, by mouth) for 10 days in combination with $100 \mu \mathrm{g} / \mathrm{ml}$ nicotine in the drinking water or given i.v. $(0.6 \mathrm{mg} / \mathrm{kg}, 5 \times /$ week) when compared with erlotinib alone.

Collectively, a possible explanation for these incongruent outcomes with nicotine alone or in combination with chemotherapy relates to differences in the route and duration of nicotine administration. The literature presents studies where nicotine was administered via s.c., intraperitoneal, and i.v. injections, as well as s.c. minipump infusions, intake via drinking water, and transdermal absorption via nicotine patches, with all lasting anywhere from 6 days to 46 weeks. Although osmotic minipumps allow for steady-state plasma levels of nicotine similar to those achieved in humans either between cigarettes or during NRT (Matta et al., 2007), only a few publications used this technology; another group used a transdermal patch, which releases nicotine in a similar manner as the s.c. pump (Davis et al., 2009). Approximately half of the studies were performed with nicotine being ingested via the drinking water, which achieves a similar effect as the minipump, with relatively stable plasma concentrations of nicotine when compared with intermittent injections (Rowell et al., 1983). 
TABLE 3

In vitro effects of nicotine on lung cancer under nonphysiologic conditions and/or with nonpharmacological concentrations of nicotine

\begin{tabular}{|c|c|c|c|c|c|c|}
\hline $\begin{array}{l}\text { Lung Cancer } \\
\text { Cell Line }\end{array}$ & Nicotine & $\begin{array}{l}\text { Duration of } \\
\text { Treatment }\end{array}$ & $\begin{array}{c}\text { Serum } \\
\text { Concentration }\end{array}$ & $\begin{array}{l}\text { Cellular Response } \\
\text { (Assay) }\end{array}$ & $\begin{array}{l}\text { Result (Relative to } \\
\text { Control) }\end{array}$ & Reference \\
\hline \multirow[t]{2}{*}{ H460, H157 } & $0.01-$ & 7 days & $10 \%$ & Viability (MTT) & $\begin{array}{l}\text { H460: } 5 \% \text { increase } \\
\quad(10,100 \mu \mathrm{M}), 5 \% \\
\text { decrease }(1 \mathrm{mM})\end{array}$ & Chen et al. (2002) \\
\hline & $1 \mathrm{mM}$ & & & & $\begin{array}{l}\text { H157: } 5 \% \text { decrease } \\
\quad(10 \mu \mathrm{M}), 5 \% \\
\text { increase }(0.1-1 \mathrm{mM})\end{array}$ & \\
\hline $201 \mathrm{~T}$ & $10 \mu \mathrm{M}$ & $48 \mathrm{~h}$ & $10 \%$ & Viability (MTS) & No effect & Carlisle et al. (2007) \\
\hline $\mathrm{H} 460$ & $10 \mathrm{nM}, 0.01-1 \mathrm{mM}$ & 5 days & $10 \%$ & $\begin{array}{l}\text { Viability (Cell } \\
\text { Titer-Glo) }\end{array}$ & $\begin{array}{c}12.5 \%-50 \% \text { increase } \\
(10 \mathrm{nM}, 10-100 \mu \mathrm{M}), * \\
\text { no effect }(1 \mathrm{mM})\end{array}$ & Zheng et al. (2007) \\
\hline A549, H1299 & $1 \mathrm{nM}$ to $10 \mathrm{mM}$ & $72 \mathrm{~h}$ & Not indicated & Viability (MTT) & $\begin{array}{l}\text { A549: } 5 \%-18 \% \\
\text { increase }(1 \mathrm{nM} \text { to } \\
10 \mu \mathrm{M}), \text { no effect } \\
(100 \mu \mathrm{M}), 5 \%-40 \% \\
\text { decrease } \\
(1-10 \mathrm{mM})^{\dagger} \\
\text { H1299: } 10 \%-30 \% \\
\text { increase } \\
(1-100 \mathrm{nM}), \text { no } \\
\text { effect }(1-100 \mu \mathrm{M}), \\
40 \%-80 \% \text { decrease } \\
(1-10 \mathrm{mM})^{\dagger}\end{array}$ & $\begin{array}{l}\text { Puliyappadamba } \\
\text { et al. (2010) }\end{array}$ \\
\hline H446 & $2.5-15 \mu \mathrm{M}$ & $12-72 \mathrm{~h}$ & $10 \%$ & Viability (MTT) & $0 \%-85 \%$ decrease $^{\dagger}$ & Zeng et al. (2012) \\
\hline A549 & $0.01,10 \mu \mathrm{M}$ & $24 \mathrm{~h}$ & $10 \%$ & Viability (MTS) & $\begin{array}{l}\text { No effect }(0.01 \mu \mathrm{M}) \text {, } \\
75 \% \text { decrease } \\
\quad(10 \mu \mathrm{M})^{*}\end{array}$ & Gao et al. (2016) \\
\hline \multirow[t]{2}{*}{ A549, H1975 } & $10 \mathrm{nM}$ to $100 \mu \mathrm{M}$ & $48 \mathrm{~h}$ & $\begin{array}{l}0 \% \text { for } 72 \mathrm{~h}, \\
\text { then treated }\end{array}$ & Viability (MTS) & $\begin{array}{l}\text { A549: } 12.5 \% \text { increase } \\
\text { (50 nM to } 100 \mu \mathrm{M}), * \\
\text { H1975: } \\
\text { no effect }\end{array}$ & $\begin{array}{l}\text { Mucchietto et al. } \\
\text { (2017) }\end{array}$ \\
\hline & & & & $\begin{array}{l}\text { Proliferation } \\
\quad \text { (cell counting) }\end{array}$ & $\begin{array}{l}\text { A549: } 33 \%-66 \% \\
\text { increase, }{ }^{*} \text { H1975: } \\
\text { no effect }\end{array}$ & \\
\hline A549 & $0.5-10 \mu \mathrm{M}$ & $72 \mathrm{~h}$ & $0 \%$ & Growth (BrdU) & $0 \%-9 \%$ increase & $\begin{array}{l}\text { Jarzynka et al. } \\
(2006)\end{array}$ \\
\hline Line1 & $1 \mu \mathrm{M}$ & $18 \mathrm{~h}$ & $\begin{array}{l}0 \% \text { for } 72 \mathrm{~h}, \\
\text { then treated }\end{array}$ & Growth (BrdU) & $180 \%$ increase $^{\dagger}$ & Davis et al. (2009) \\
\hline LKR & $1 \mu \mathrm{M}$ & $24 \mathrm{~h}$ & $\begin{array}{l}0.2 \% \text { for } 24 \mathrm{~h}, \\
\text { then treated }\end{array}$ & $\begin{array}{l}\text { Growth }\left(\left[{ }^{3} \mathrm{H}\right]-\right. \\
\text { thymidine })\end{array}$ & $200 \%$ increase $^{\dagger}$ & $\begin{array}{l}\text { Nishioka et al. } \\
(2010)\end{array}$ \\
\hline A549, H1299 & $1 \mathrm{nM}$ to $100 \mu \mathrm{M}$ & $24 \mathrm{~h}$ & Not indicated & $\begin{array}{l}\text { Growth }\left(\left[{ }^{3} \mathrm{H}\right]-\right. \\
\text { thymidine })\end{array}$ & $\begin{array}{l}5 \%-20 \% \text { increase } \\
(1 \mathrm{nM} \text { to } 1 \mu \mathrm{M}))^{\dagger} \\
5 \%-20 \% \text { decrease } \\
(10-100 \mu \mathrm{M})^{\dagger}\end{array}$ & $\begin{array}{l}\text { Puliyappadamba } \\
\text { et al. (2010) }\end{array}$ \\
\hline A549 & $1 \mu \mathrm{M}$ & $18 \mathrm{~h}$ & $\begin{array}{l}0 \% \text { for } 36 \mathrm{~h} \text {, } \\
\text { then treated }\end{array}$ & Growth (BrdU) & $150 \%$ increase $*$ & $\begin{array}{l}\text { Dasgupta et al. } \\
\text { (2011) }\end{array}$ \\
\hline A549, H1650 & $1 \mu \mathrm{M}$ & $\begin{array}{l}18 \mathrm{~h} \\
24 \mathrm{~h}\end{array}$ & $\begin{array}{l}0 \% \text { for } 24 \mathrm{~h}, \\
\text { then treated }\end{array}$ & $\begin{array}{l}\text { Growth (BrdU) } \\
\text { Invasion (Boyden) }\end{array}$ & $\begin{array}{l}175 \%-180 \% \text { increase }^{\dagger} \\
90 \%-100 \% \text { increase }^{\dagger}\end{array}$ & Pillai et al. (2011) \\
\hline A549, H1650 & $1 \mu \mathrm{M}$ & $\begin{array}{l}18 \mathrm{~h} \\
24 \mathrm{~h}\end{array}$ & $\begin{array}{l}0 \% \text { for } 24 \mathrm{~h}, \\
\text { then treated }\end{array}$ & $\begin{array}{l}\text { Growth (BrdU) } \\
\text { Invasion (Boyden) }\end{array}$ & $\begin{array}{l}75 \%, 100 \% \text { increase }^{\dagger} \\
75 \%, 150 \% \text { increase }^{\dagger}\end{array}$ & Nair et al. (2014) \\
\hline LLC & $1 \mathrm{pM}$ to $100 \mu \mathrm{M}$ & Not indicated & $0.1 \%$ & $\begin{array}{l}\text { Proliferation } \\
\quad \text { (cell counting) }\end{array}$ & No effect & $\begin{array}{l}\text { Heeschen et al. } \\
\text { (2001) }\end{array}$ \\
\hline H157, H1703 & $100 \mathrm{nM}$ & 3 days $^{a}$ & $0.1 \%$ & $\begin{array}{l}\text { Proliferation } \\
\quad \text { (cell counting) }\end{array}$ & $50 \%-95 \%$ increase $*$ & $\begin{array}{l}\text { Tsurutani et al. } \\
\text { (2005) }\end{array}$ \\
\hline H1299 & $10 \mathrm{nM}$ & $\begin{array}{l}\text { Previously } \\
\text { treated for } \\
72 \mathrm{~h}, \text { then } \\
\text { seeded }\end{array}$ & Not indicated & $\begin{array}{l}\text { Proliferation (colony } \\
\quad \text { formation) }\end{array}$ & $150 \%$ increase $^{\dagger}$ & $\begin{array}{l}\text { Puliyappadamba } \\
\text { et al. (2010) }\end{array}$ \\
\hline \multirow[t]{2}{*}{ A549 } & $0.01-10 \mu \mathrm{M}$ & $18 \mathrm{~h}$ & $\begin{array}{l}0 \% \text { (before } \\
\text { and during } \\
\text { treatment) }\end{array}$ & Invasion (Boyden) & $\begin{array}{c}10 \% \text { decrease }(10 \mathrm{nM}) \\
50 \%-160 \% \text { increase } \\
(0.1-1 \mu \mathrm{M}), 90 \% \\
\text { increase }(10 \mu \mathrm{M})^{\dagger}\end{array}$ & $\begin{array}{l}\text { Dasgupta et al. } \\
\text { (2009) }\end{array}$ \\
\hline & & $24 \mathrm{~h}$ & $\begin{array}{l}0 \% \text { (during } \\
\quad \text { treatment) }\end{array}$ & $\begin{array}{l}\text { Migration (wound } \\
\text { healing) }\end{array}$ & $\begin{array}{l}10 \%-100 \% \text { increase } \\
\quad(0.01-1 \mu \mathrm{M}), 25 \% \\
\text { increase }(10 \mu \mathrm{M})^{\dagger}\end{array}$ & \\
\hline \multirow[t]{2}{*}{ N417 } & $500 \mu \mathrm{M}$ & $\begin{array}{l}\text { Previously } \\
\text { treated for }\end{array}$ & $10 \%$ & $\begin{array}{l}\text { Proliferation (colony } \\
\text { formation) }\end{array}$ & $130 \%$ increase* & $\begin{array}{l}\text { Martínez-García } \\
\text { et al. (2010) }\end{array}$ \\
\hline & & $\begin{array}{l}7 \text { days, then } \\
\text { seeded }\end{array}$ & $0.5 \%$ & $\begin{array}{l}\text { Migration } \\
\text { (Transwell) }\end{array}$ & $55 \%$ increase* & \\
\hline \multirow[t]{2}{*}{ A549, H1299 } & $0.1-1 \mu \mathrm{M}$ & $36 \mathrm{~h}$ & $\begin{array}{l}0 \% \text { for } 24 \mathrm{~h} \text {, } \\
\text { treated, then }\end{array}$ & $\begin{array}{l}\text { Proliferation (cell } \\
\text { counting) }\end{array}$ & $50 \%-200 \%$ increase & Liu et al. (2015) \\
\hline & & & seeded & $\begin{array}{l}\text { Migration } \\
\quad \text { (wound healing) }\end{array}$ & $30 \%$ increase* & \\
\hline
\end{tabular}


TABLE 3-Continued

\begin{tabular}{|c|c|c|c|c|c|c|}
\hline $\begin{array}{l}\text { Lung Cancer } \\
\text { Cell Line }\end{array}$ & Nicotine & $\begin{array}{l}\text { Duration of } \\
\text { Treatment }\end{array}$ & $\begin{array}{c}\text { Serum } \\
\text { Concentration }\end{array}$ & $\begin{array}{l}\text { Cellular Response } \\
\text { (Assay) }\end{array}$ & $\begin{array}{l}\text { Result (Relative to } \\
\text { Control) }\end{array}$ & Reference \\
\hline $\begin{array}{c}\text { A549, H1650, } \\
\text { H1975, } \\
\text { H23. H358 }\end{array}$ & $1 \mu \mathrm{M}$ & $24 \mathrm{~h}$ & $\begin{array}{l}0 \% \text { for } 36 \mathrm{~h} \text {, } \\
\text { then treated }\end{array}$ & Invasion (Boyden) & $120 \%-430 \%$ increase* & Pillai et al. (2015) \\
\hline \multirow[t]{3}{*}{ A549, H1299 } & $1 \mu \mathrm{M}$ & $48 \mathrm{~h}$ & \multirow{3}{*}{$\begin{array}{l}0 \% \text { for } 12 \mathrm{~h}, \\
\text { then treated }\end{array}$} & Viability (CCK-8) & $25 \%, 40 \%$ increase $*$ & \multirow[t]{3}{*}{ Gong et al. (2014) } \\
\hline & $10 \mathrm{nM}$ & $48 \mathrm{~h}$ & & $\begin{array}{l}\text { Invasion } \\
\quad \text { (Transwell) }\end{array}$ & $75 \%$ increase* & \\
\hline & & $\begin{array}{l}48 \mathrm{~h} \\
72 \mathrm{~h}\end{array}$ & & $\begin{array}{l}\text { Migration } \\
\text { (wound healing) }\end{array}$ & $25 \%, 30 \%$ increase $*$ & \\
\hline A549, H460 & $1 \mu \mathrm{M}$ & $48-96 \mathrm{~h}$ & $0 \%-5 \%$ & $\begin{array}{l}\text { Viability } \\
\text { (MTS, MTT) }\end{array}$ & $\begin{array}{l}\text { A549: no effect, } \\
\text { H460: } 25 \% \text { increase } \\
\text { with } 0 \% \text { serum } \\
\text { at } 96 \mathrm{~h}^{*}\end{array}$ & Kyte et al. (2018) \\
\hline \multirow[t]{2}{*}{ A549 } & $5 \mu \mathrm{M}$ & $48 \mathrm{~h}$ & $10 \%$ & Invasion (QCM) & $950 \%$ increase* & \multirow[t]{2}{*}{ Zhang et al. (2007) } \\
\hline & $5,10 \mu \mathrm{M}$ & $16 \mathrm{~h}$ & & $\begin{array}{l}\text { Angiogenesis } \\
(\mathrm{HIF}-1 \alpha)\end{array}$ & $\begin{array}{l}1000 \%, 1100 \% \\
\text { increase* }\end{array}$ & \\
\hline $\begin{array}{l}\text { A549, H1299, } \\
\text { H1975 }\end{array}$ & & & & & $\begin{array}{l}\text { H1299: } 13 \%, 14 \% \\
\text { increase, H1975: } \\
65 \% \text { increase } \\
(10 \mu \mathrm{M}), * 40 \% \\
\text { increase }(50 \mu \mathrm{M})\end{array}$ & \multirow{3}{*}{ Ma et al. (2014) } \\
\hline A549 & $5 \mu \mathrm{M}$ & $16 \mathrm{~h}$ & & $\begin{array}{l}\text { Angiogenesis } \\
(\mathrm{HIF}-1 \alpha)\end{array}$ & $25 \%$ increase & \\
\hline A549 & $5 \mu \mathrm{M}$ & $16 \mathrm{~h}$ & & $\begin{array}{l}\text { Angiogenesis } \\
\text { (VEGF) }\end{array}$ & $150 \%$ increase & \\
\hline \multirow[t]{2}{*}{ A549 } & $5 \mu \mathrm{M}$ & $36 \mathrm{~h}$ & $10 \%$ & $\begin{array}{l}\text { Invasion } \\
\quad \text { (Transwell) }\end{array}$ & $230 \%$ increase ${ }^{*}$ & \multirow[t]{2}{*}{ Shi et al. (2015) } \\
\hline & & $16 \mathrm{~h}$ & & $\begin{array}{l}\text { Angiogenesis (VEGF } \\
\text { protein, mRNA) }\end{array}$ & $\begin{array}{l}25 \% \text { increase, } * 700 \% \\
\text { increase }\end{array}$ & \\
\hline
\end{tabular}

BrdU, bromodeoxyuridine; CCK-8, cell counting kit-8; HIF-1 $\alpha$, hypoxia-inducible factor 1- $\alpha$; LLC, Lewis lung carcinoma; MTS, (3-(4,5-dimethylthiazol-2-yl)-5-(3-

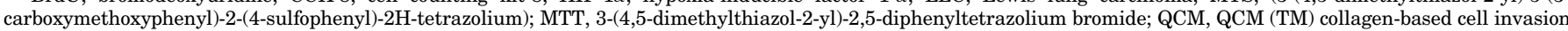
assay; T1, primary human lung carcinoma; VEGF, vascular endothelial growth factor.

${ }^{a}$ Nicotine was replaced every $24 \mathrm{~h}$.

*Statistically significant.

Statistical significance not indicated.

The route of administration could play a role in how the nAChRs are responding to nicotine over time. For example, chronic exposure of nAChRs to nicotine via a s.c. minipump or via drinking water could cause prolonged desensitization of nAChRs, which has been shown to occur in neuroblastoma cells chronically treated with nicotine (Sokolova et al., 2005). In contrast, Sokolova et al. (2005) also showed that acute exposure to nicotine could produce $\mathrm{nAChR}$ activation, followed by rapid desensitization and/or reduced responsiveness. After washout and repeat exposure to nicotine, the $\mathrm{nAChRs}$ recover sensitivity to nicotine; this response could be occurring during intermittent injections of nicotine. Therefore, it is possible that the duration of tumor exposure to nicotine, which can be influenced by the route of administration, could be contributing to the induction or inhibition of nAChR-mediated signaling.

However, unless the plasma concentration of nicotine is monitored over time, it is difficult to determine how much nicotine the mice are receiving systemically. AlSharari et al. (2013) determined the plasma concentration of nicotine following various dosing regimens in C57BL/6J mice: $0.5-2 \mathrm{mg} / \mathrm{kg}$ s.c. twice daily for 10 days $(51-163 \mathrm{ng} / \mathrm{ml}$ or $314-1005 \mathrm{nM})$,
$2.5-25 \mathrm{mg} / \mathrm{kg}$ per day s.c. via $14-$ day minipump (13-97 ng/ml or $80-598 \mathrm{nM}$ ), and $25-100 \mu \mathrm{g} / \mathrm{ml}$ by mouth for 10 days $(18-27.5 \mathrm{ng} / \mathrm{ml}$ or $111-170 \mathrm{nM})$. Although direct comparisons cannot be made between animals and humans, this study demonstrates that the nicotine concentrations being achieved via s.c. or oral administration in mice, the predominant animal model for cancer and CIPN studies, are similar to that of circulating nicotine levels in humans using NRT and are expected to be predictive of patient response.

\section{The Complexity of the Problem}

It is challenging to determine which specific experimental factors and/or properties of nicotine are responsible for the contradictory observations in the literature. One possibility worthy of consideration involves the initial transient response to nicotine, including the phosphorylation of Akt, a key player in proliferative and antiapoptotic pathways. Jin et al. (2004) demonstrated a peak of Akt phosphorylation at 30-60 minutes postnicotine $(1 \mu \mathrm{M})$ treatment in A549 NSCLC cells that returns to baseline levels at 120 minutes. 
TABLE 4

In vitro effects of nicotine in combination with chemotherapy on lung cancer

\begin{tabular}{|c|c|c|c|c|c|c|c|}
\hline $\begin{array}{l}\text { Lung Cancer } \\
\text { Cell Line }\end{array}$ & Nicotine & Chemotherapy & Duration of Treatment & $\begin{array}{c}\text { Serum } \\
\text { Concentration }\end{array}$ & $\begin{array}{c}\text { Cellular Response } \\
\text { (Assay) }\end{array}$ & $\begin{array}{l}\text { Result (Relative to } \\
\text { Chemotherapy Alone) }\end{array}$ & Reference \\
\hline A549 & $1 \mu \mathrm{M}$ & Cisplatin $40 \mu \mathrm{M}$ & $24 \mathrm{~h}$ & $10 \%$ & $\begin{array}{l}\text { Apoptosis } \\
\quad(\text { annexin V) }\end{array}$ & $30 \%$ decrease $^{\dagger}$ & Jin et al. (2004) \\
\hline A549, H157 & $1 \mu \mathrm{M}$ & Cisplatin $40 \mu \mathrm{M}$ & $\begin{array}{c}6 \%-48 \mathrm{~h} \\
24 \mathrm{~h}\end{array}$ & $10 \%$ & $\begin{array}{l}\text { Apoptosis } \\
\quad(\text { annexin V) }\end{array}$ & $\begin{array}{l}0 \%-40 \% \text { decrease }^{\dagger} \\
40 \% \text { decrease }^{\dagger}\end{array}$ & $\begin{array}{l}\text { Xin and Deng } \\
(2005)\end{array}$ \\
\hline LKR & $1 \mu \mathrm{M}$ & Cisplatin $5 \mu \mathrm{M}$ & $\begin{array}{l}\text { Nicotine for } 1 \mathrm{~h} \text {, then } \\
\text { cisplatin for } 24 \mathrm{~h} \\
\text { Nicotine for } 1 \mathrm{wk}, \\
\text { then cisplatin for } \\
24 \mathrm{~h}\end{array}$ & $10 \%$ & $\begin{array}{l}\text { Apoptosis (sub- } \\
\text { G1) }\end{array}$ & $\begin{array}{l}20 \% \text { decrease }^{\dagger} \\
5 \% \text { decrease }^{\dagger}\end{array}$ & $\begin{array}{l}\text { Nishioka et al. } \\
(2010)\end{array}$ \\
\hline H446 & $0.1-1 \mu \mathrm{M}$ & Cisplatin $10 \mu \mathrm{M}$ & $\begin{array}{c}12-72 \mathrm{~h} \\
36 \mathrm{~h}\end{array}$ & $10 \%$ & $\begin{array}{l}\text { Viability (MTT) } \\
\text { Apoptosis } \\
\text { (AV/PI) }\end{array}$ & $\begin{array}{l}13 \%-20 \% \text { increase }^{\dagger} \\
\text { No effect }(0.1-0.5 \\
\mu \mathrm{M}) \text {, } \\
15 \% \text { decrease } \\
(1 \mu \mathrm{M})^{*}\end{array}$ & Zeng et al. (2012) \\
\hline H5800, LKR & $0.5 \mu \mathrm{M}$ & Cisplatin $0.6 \mu \mathrm{M}$ & $\begin{array}{l}\text { Nicotine for } 24 \mathrm{~h} \text {, } \\
\text { then cotreatment } \\
\text { of } 48 \mathrm{~h}\end{array}$ & $10 \%$ & $\begin{array}{l}\text { Apoptosis } \\
\quad(\text { annexin V) }\end{array}$ & $60 \%$ decrease* & $\begin{array}{l}\text { Nishioka et al. } \\
\text { (2014) }\end{array}$ \\
\hline A549 & $1 \mu \mathrm{M}$ & Cisplatin $20 \mu \mathrm{M}$ & $\begin{array}{l}\text { Nicotine for } 24 \mathrm{~h} \text {, } \\
\text { then cisplatin for } \\
24 \mathrm{~h}\end{array}$ & $10 \%$ & $\begin{array}{r}\text { Apoptosis } \\
(\mathrm{AV} / \mathrm{PI})\end{array}$ & $40 \%$ decrease* & Liu et al. (2015) \\
\hline A549 & $1 \mu \mathrm{M}$ & $\begin{array}{l}\text { Cisplatin } 35 \mu \mathrm{M} \\
\text { Etoposide } 20 \mu \mathrm{M} \\
\text { Cisplatin } 35 \mu \mathrm{M} \\
\text { Etoposide } 20 \mu \mathrm{M}\end{array}$ & $\begin{array}{l}\text { Nicotine for } 24 \mathrm{~h} \text {, } \\
\text { then cotreatment } \\
\text { of } 24 \mathrm{~h}\end{array}$ & $10 \%$ & $\begin{array}{l}\text { Viability (MTT) } \\
\text { Apoptosis (DNA } \\
\text { fragmentation } \\
\text { ELISA) }\end{array}$ & $\begin{array}{l}25 \% \text { increase* } \\
35 \% \text { increase* } \\
35 \% \text { decrease } \\
20 \% \text { decrease }\end{array}$ & $\begin{array}{l}\text { Zhang et al. } \\
\text { (2009) }\end{array}$ \\
\hline H1299 & $1 \mu \mathrm{M}$ & $\begin{array}{l}\text { Cisplatin } 40 \mu \mathrm{M} \\
\text { Etoposide } 40 \mu \mathrm{M}\end{array}$ & $96 \mathrm{~h}$ & $10 \%$ & $\begin{array}{l}\text { Apoptosis } \\
(\text { annexin V) }\end{array}$ & $\begin{array}{l}40 \% \text { decrease* } \\
30 \% \text { decrease }\end{array}$ & Zhao et al. (2009) \\
\hline A549 & $1 \mu \mathrm{M}$ & Doxorubicin $10 \mu \mathrm{M}$ & $\begin{array}{l}\text { Nicotine for } 1 \mathrm{~h} \text {, then } \\
\text { cotreatment of } \\
48 \mathrm{~h}\end{array}$ & $10 \%$ & $\begin{array}{l}\text { Viability (XTT) } \\
\text { Apoptosis } \\
\quad \text { (caspase-Glo } \\
\text { 3/7) }\end{array}$ & $\begin{array}{l}25 \% \text { increase* } \\
300 \% \text { decrease* }\end{array}$ & $\begin{array}{l}\text { Nakada et al. } \\
(2012)\end{array}$ \\
\hline PC9, HCC827 & $1 \mu \mathrm{M}$ & $\begin{array}{l}\text { Erlotinib } 1 \mathrm{nM} \text { to } \\
\quad 5 \mu \mathrm{M}\end{array}$ & $72 \mathrm{~h}$ & $10 \%$ & Viability (MTS) & $\begin{array}{l}\mathrm{IC}_{50} 31 \mathrm{nM} \\
\quad \rightarrow 43 \mathrm{nM}(\mathrm{PC} 9), * \\
\mathrm{IC}_{50} 46 \mathrm{nM} \rightarrow \\
140 \mathrm{nM}\end{array}$ & Li et al. (2015) \\
\hline $201 \mathrm{~T}$ & $1 \mu \mathrm{M}$ & Gefitinib $35 \mu \mathrm{M}$ & $48 \mathrm{~h}$ & $10 \%$ & Viability (MTS) & $30 \%$ increase & $\begin{array}{l}\text { Carlisle et al. } \\
(2007)\end{array}$ \\
\hline PC9, 11-18 & $1 \mu \mathrm{M}$ & $\begin{array}{l}\text { Gefitinib } 5 \mathrm{nM} \text { to } \\
\quad 50 \mu \mathrm{M}\end{array}$ & $72 \mathrm{~h}$ & $10 \%$ & Viability (MTT) & $\begin{array}{l}\mathrm{IC}_{50} 24 \mathrm{nM} \rightarrow \\
\quad 22 \mathrm{nM}, \\
0.35 \mu \mathrm{M} \rightarrow 0.33 \\
\quad \mu \mathrm{M}\end{array}$ & $\begin{array}{l}\text { Togashi et al. } \\
\text { (2015) }\end{array}$ \\
\hline & & & $\begin{array}{l}\text { Nicotine for } 3 \mathrm{mo} \text {, } \\
\text { then cotreatment } \\
\text { of } 72 \mathrm{~h}\end{array}$ & & & $\begin{array}{l}\mathrm{IC}_{50} 24 \mathrm{nM} \rightarrow \\
\quad 76 \mathrm{nM}, * 0.35 \mu \mathrm{M} \\
\quad \rightarrow 1.09 \mu \mathrm{M}^{*}\end{array}$ & \\
\hline \multirow[t]{4}{*}{ A549, H460 } & \multirow[t]{4}{*}{$1 \mu \mathrm{M}$} & Paclitaxel $50 \mathrm{nM}$ & $\begin{array}{l}\text { Paclitaxel for } 24 \mathrm{~h} \text {, } \\
24 \text {-h drug-free, } \\
\text { nicotine } \\
\text { for } 24 \mathrm{~h}\end{array}$ & \multirow[t]{4}{*}{$10 \%$} & $\begin{array}{l}\text { Proliferation } \\
\text { (colony } \\
\text { formation) }\end{array}$ & No effect & \multirow[t]{4}{*}{ Kyte et al. (2018) } \\
\hline & & Paclitaxel 50 nM & $\begin{array}{l}\text { Nicotine for } 24 \mathrm{~h} \text {, } \\
\text { then } \\
\text { 24-h cotreatment }\end{array}$ & & $\begin{array}{l}\text { Proliferation } \\
\quad \text { (cell counting) }\end{array}$ & No effect & \\
\hline & & Paclitaxel 100 nM & $48 \mathrm{~h}$ & & $\begin{array}{l}\text { Apoptosis } \\
\text { (AV/PI) }\end{array}$ & No effect & \\
\hline & & Paclitaxel 100 nM & $48 \mathrm{~h}$ & & $\begin{array}{l}\text { Apoptosis (sub- } \\
\text { G1) }\end{array}$ & No effect & \\
\hline
\end{tabular}

AV/PI, annexin V/propidium iodide; ELISA, enzyme-linked immunosorbent assay; MTS, (3-(4,5-dimethylthiazol-2-yl)-5-(3-carboxymethoxyphenyl)-2-(4-sulfophenyl)-2Htetrazolium); MTT, 3-(4,5-dimethylthiazol-2-yl)-2,5-diphenyltetrazolium bromide; XTT, 2,3-Bis(2-methoxy-4-nitro-5-sulfophenyl)-2H-tetrazolium-5-carboxanilide inner salt.

${ }^{\dagger}$ Statistical significance not indicated.

*Statistically significant.

Depending on the time of observation postnicotine treatment, it is possible that activation of the phosphatidylinositol 3-kinase/Akt pathway is contributing to a temporary enhancement of proliferation, which dissipates even in the presence of nicotine. In addition, chronic nicotine treatment may be inducing prolonged alterations in $\mathrm{nAChR}$ expression. For example, exposure to $100 \mathrm{nM}$ to $10 \mu \mathrm{M}$ nicotine for 96 hours leads to a significant upregulation of $\alpha 7 \mathrm{nAChR}$ expression in H520 small cell lung cancer cells (Brown et al.,
2013). Yet it appears that this increased receptor expression does not persist in the absence of nicotine. Studies in human bronchial epithelial cells revealed that $100 \mathrm{nM}$ nicotine significantly increases the expression of genes that encode nAChR subunits, including CHRNA1, CHRNA5, and CHRNA7 within 72 hours, but, following removal of nicotine, the expression levels return to baseline at 144 hours (Lam et al., 2007). This observation raises the question of how quickly we might expect to observe similar changes in 
TABLE 5

In vitro effects of nicotine in combination with chemotherapy on lung cancer under nonphysiologic conditions and/or with nonpharmacological concentrations of nicotine

\begin{tabular}{|c|c|c|c|c|c|c|c|}
\hline $\begin{array}{l}\text { Lung Cancer } \\
\text { Cell Line }\end{array}$ & Nicotine & Chemotherapy & $\begin{array}{l}\text { Duration of } \\
\text { Treatment }\end{array}$ & $\begin{array}{c}\text { Serum } \\
\text { Concentration }\end{array}$ & $\begin{array}{l}\text { Cellular } \\
\text { Response } \\
\text { (Assay) }\end{array}$ & $\begin{array}{l}\text { Result (Relative to } \\
\text { Chemotherapy Alone) }\end{array}$ & Reference \\
\hline A549 & $1 \mu \mathrm{M}$ & $\begin{array}{r}\text { Cisplatin } \\
20 \mu \mathrm{M}\end{array}$ & $24 \mathrm{~h}$ & $\begin{array}{l}0 \% \text { for } 36 \mathrm{~h}, \\
\text { then treated }\end{array}$ & $\begin{array}{l}\text { Apoptosis } \\
\text { (TUNEL) }\end{array}$ & $40 \%$ decrease* & $\begin{array}{l}\text { Dasgupta et al. } \\
\quad(2011)\end{array}$ \\
\hline \multirow[t]{2}{*}{ H446 } & \multirow[t]{2}{*}{$2.5-15 \mu \mathrm{M}$} & \multirow[t]{2}{*}{$\begin{array}{l}\text { Cisplatin } \\
10 \mu \mathrm{M}\end{array}$} & $12-72 \mathrm{~h}$ & $10 \%$ & $\begin{array}{l}\text { Viability } \\
\text { (MTT) }\end{array}$ & $\begin{array}{l}10 \%-20 \% \text { increase } \\
\quad(2.5 \mu \mathrm{M}) \\
0 \%-50 \% \text { decrease } \\
\quad(5-15 \mu \mathrm{M})^{\dagger}\end{array}$ & Zeng et al. (2012) \\
\hline & & & $36 \mathrm{~h}$ & & $\begin{array}{l}\text { Apoptosis } \\
\text { (AV/PI) }\end{array}$ & $25 \%-50 \%$ decrease $*$ & \\
\hline \multirow[t]{3}{*}{$\begin{array}{l}\text { A549, H1299, } \\
\quad \text { H23 }\end{array}$} & \multirow[t]{3}{*}{$1 \mu \mathrm{M}$} & $\begin{array}{l}\text { Cisplatin } \\
20 \mu \mathrm{M}\end{array}$ & \multirow[t]{3}{*}{$36 \mathrm{~h}$} & \multirow[t]{3}{*}{$0 \%$} & \multirow[t]{3}{*}{$\begin{array}{l}\text { Apoptosis } \\
\text { (TUNEL) }\end{array}$} & $20 \%-40 \%$ decrease ${ }^{\dagger}$ & \multirow[t]{3}{*}{$\begin{array}{l}\text { Dasgupta et al. } \\
\quad(2006)\end{array}$} \\
\hline & & $\begin{array}{l}\text { Gemcitabine } \\
\qquad 20 \mu \mathrm{M}\end{array}$ & & & & $20 \%-25 \%$ decrease ${ }^{\dagger}$ & \\
\hline & & $\begin{array}{l}\text { Paclitaxel } \\
20 \mu \mathrm{M}\end{array}$ & & & & $25 \%-50 \%$ decrease $^{\dagger}$ & \\
\hline \multirow[t]{4}{*}{ N417 } & \multirow{4}{*}{$\begin{array}{l}\text { Previous nicotine } \\
\text { exposure }(500 \mu \mathrm{M} \\
\text { for } 7 \text { days })\end{array}$} & $\begin{array}{l}\text { Cisplatin } \\
\qquad(5-100 \mu \mathrm{M})\end{array}$ & $48 \mathrm{~h}$ & \multirow[t]{4}{*}{$10 \%$} & \multirow[t]{4}{*}{$\begin{array}{r}\text { Viability } \\
\text { (MTT) }\end{array}$} & $50 \%$ increase* & \multirow[t]{4}{*}{$\begin{array}{l}\text { Martínez-García } \\
\text { et al. (2010) }\end{array}$} \\
\hline & & $\begin{array}{l}\text { Etoposide } \\
\quad(5-100 \mu \mathrm{M})\end{array}$ & & & & $50 \%$ increase ${ }^{*}$ & \\
\hline & & $\begin{array}{l}\text { Mitomycin } \\
\quad(5-50 \mu \mathrm{M})\end{array}$ & & & & $\begin{array}{l}\mathrm{IC}_{50} 10 \mu \mathrm{M} \rightarrow \\
20 \mu \mathrm{M}^{*}\end{array}$ & \\
\hline & & $\begin{array}{l}\text { Paclitaxel } \\
\qquad(5-100 \mu \mathrm{M})\end{array}$ & & & & $\begin{array}{l}\mathrm{IC}_{50} 35 \mu \mathrm{M} \rightarrow \\
\quad 70 \mu \mathrm{M}^{*}\end{array}$ & \\
\hline $201 \mathrm{~T}$ & $10 \mu \mathrm{M}$ & $\begin{array}{l}\text { Gefitinib } \\
35 \mu \mathrm{M}\end{array}$ & $48 \mathrm{~h}$ & $10 \%$ & $\begin{array}{l}\text { Viability } \\
\text { (MTS) }\end{array}$ & $\begin{array}{l}47 \% \text { increase } \\
(10 \mu \mathrm{M})^{*}\end{array}$ & $\begin{array}{l}\text { Carlisle et al. } \\
\text { (2007) }\end{array}$ \\
\hline A549 & $1 \mu \mathrm{M}$ & $\begin{array}{l}\text { Gemcitabine } \\
\qquad 10 \mu \mathrm{M}\end{array}$ & $36 \mathrm{~h}$ & $\begin{array}{l}0 \% \text { for } 24 \mathrm{~h}, \\
\text { then treated }\end{array}$ & $\begin{array}{l}\text { Apoptosis } \\
\text { (TUNEL) }\end{array}$ & $20 \%$ decrease* & Guo et al. (2013) \\
\hline \multirow[t]{2}{*}{ H157, H1703 } & \multirow[t]{2}{*}{$10 \mu \mathrm{M}$} & $\begin{array}{r}\text { Paclitaxel } \\
100 \mathrm{nM}\end{array}$ & $48 \mathrm{~h}$ & $0.1 \%$ & \multirow[t]{2}{*}{$\begin{array}{l}\text { Apoptosis } \\
\quad(\text { sub-G1) }\end{array}$} & $8 \%$ decrease $*$ & \multirow[t]{2}{*}{$\begin{array}{l}\text { Tsurutani et al. } \\
(2005)\end{array}$} \\
\hline & & $\begin{array}{r}\text { Etoposide } \\
100 \mu \mathrm{M}\end{array}$ & & & & $15 \%$ decrease* & \\
\hline
\end{tabular}

AV/PI, annexin V/propidium iodide; MTS, (3-(4,5-dimethylthiazol-2-yl)-5-(3-carboxymethoxyphenyl)-2-(4-sulfophenyl)-2H-tetrazolium); MTT, 3-(4,5-dimethylthiazol-2-yl)2,5-diphenyltetrazolium bromide; TUNEL, terminal deoxynucleotidyl transferase dUTP nick-end labeling.

*Statistically significant.

${ }^{\dagger}$ Statistical significance not indicated.

nAChR expression in the lung tumors of cancer patients, as well as how the initial $\mathrm{nAChR}$ expression profile differs from patient to patient and possibly determines nicotine's predominant effect.

There is also evidence that nicotine can induce both p53 and p21 tumor suppressor proteins, which could be responsible for the lack of enhanced proliferation reported by some research groups. It has previously been shown that nicotine can induce p53 and p21 at concentrations ranging from $1 \mathrm{nM}$ to $1 \mu \mathrm{M}$ in A549 NSCLC cells (Puliyappadamba et al., 2010). Both of these proteins are induced when the cell is undergoing stress, including the presence of reactive oxygen species, which has been observed in HT-29 colon cancer cells following treatment with $100 \mathrm{nM}$ nicotine (Pelissier-Rota et al., 2015). The cellular response to stress involves upregulation of $\mathrm{p} 21$, which inhibits the cyclins that normally allow for retinoblastoma protein $(\mathrm{Rb})$ phosphorylation and subsequent E2F transcription factor-mediated initiation of DNA synthesis and progression through the cell cycle (Giacinti and Giordano, 2006). Conversely, it has been observed that nicotine can activate E2F via the $\mathrm{nAChR}-\beta$-arrestin-Src-Raf-Rb pathway [see review by Schaal and Chellappan (2014)]. If the p21-mediated antiproliferative pathway is being stimulated by nicotine, then any proliferative signaling induced downstream of the nAChRs could be offset, resulting in little or no stimulation of tumor cell growth.

Another possibility is that the nicotine-mediated activation of the prosurvival and antiapoptotic nAChR downstream signaling is counterbalanced by inhibition of this same signaling downstream of the $\alpha 9 \mathrm{nAChR}$. It has been known for decades that nicotine can act as an antagonist at the $\alpha 9$ nAChR, as shown by Elgoyhen et al. (1994), where $\alpha 9 \mathrm{nAChR}$ expressing Xenopus oocytes were exposed to increasing concentrations of nicotine in the presence of acetylcholine, which led to a dose-dependent decrease in acetylcholine-evoked currents. It has also been shown in MDA-MB-231 metastatic breast cancer cells that CRISPR-Cas 9 knockout of $\alpha 9 \mathrm{nAChR}$ expression leads to a significant decrease in both migration and invasion of these cells (Huang et al., 2017). Therefore, the nAChR subtype expression profile in different lung cancer cell lines may play a role in the varying outcomes following nicotine exposure.

\section{Conclusions}

Although the findings pertaining to the effects of nicotine alone on lung tumor cells in culture are somewhat inconclusive, the evidence supporting nicotine-induced chemoresistance in vitro is relatively strong. However, additional studies with nicotine in the low nanomolar range in combination with cancer chemotherapy would provide much-needed clarity. Furthermore, there is a deficiency of data relating to the interaction of nicotine with cancer chemotherapeutic agents in vivo. Therefore, erring on the side of caution, our analysis of the literature suggests that nicotine could be tested safely in patients exhibiting CIPN who have 
TABLE 6

In vivo effects of nicotine on lung cancer

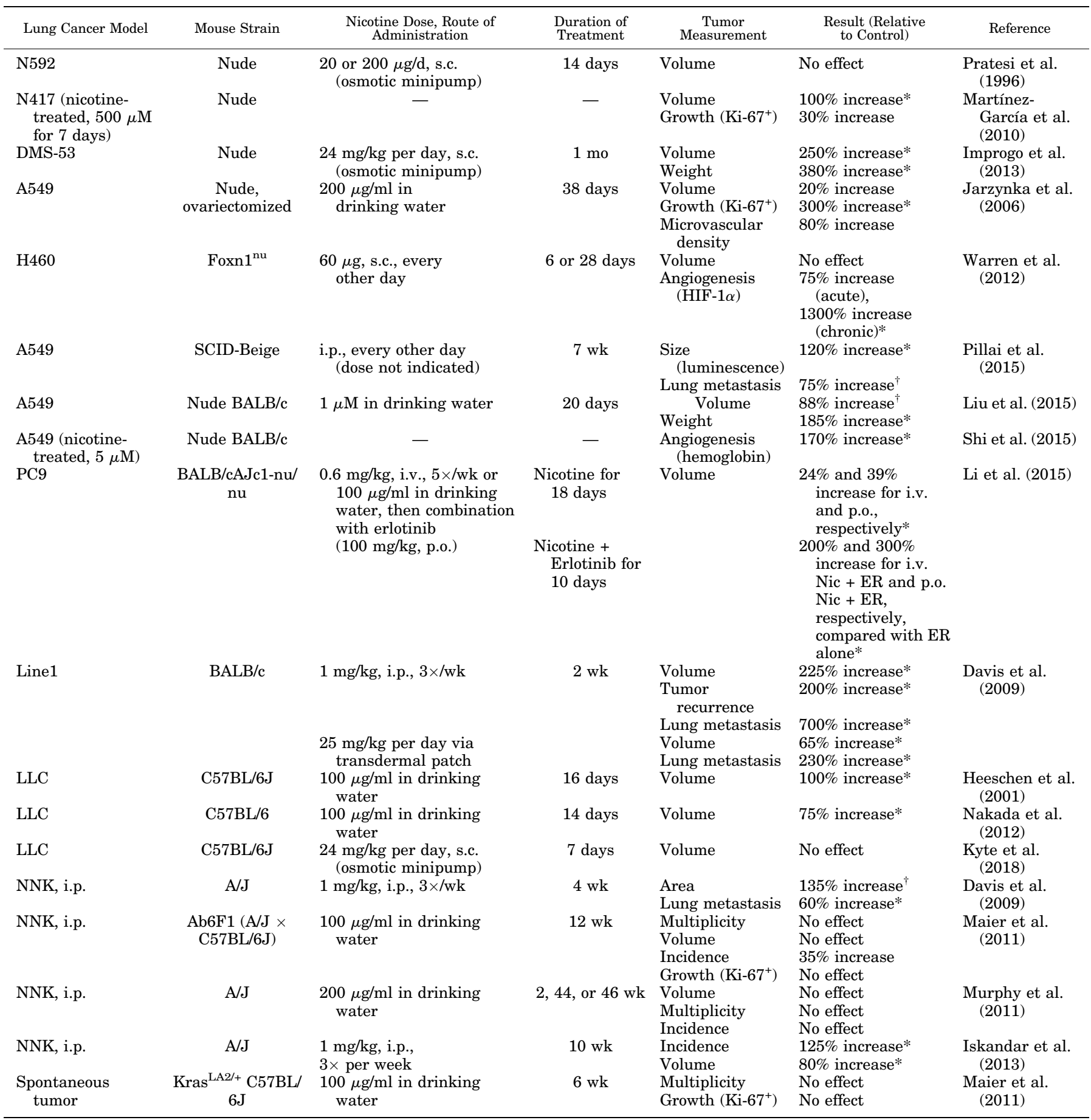

HIF-1 $\alpha$, hypoxia-inducible factor 1- $\alpha$; i.p., intraperitoneal; LLC, Lewis lung carcinoma; NNK, nicotine-derived nitrosamine ketone; p.o., oral.

*Statistically significant.

'Statistical significance not indicated.

completed chemotherapy and are cancer-free by using Food and Drug Administration-approved, commercially available nicotine patches or gum, thereby eliminating the concern for tumor growth promotion or interference with the effectiveness of chemotherapy. Finally, it should be noted that human studies have reported nicotine replacement therapy as not being a significant predictor of cancer (Murray et al., 2009).

\section{Acknowledgments}

We thank Dr. M. Imad Damaj for lending expertise in both nicotine and behavioral pharmacology. 


\section{Authorship Contributions}

Performed data analysis: Kyte.

Wrote or contributed to the writing of the manuscript: Kyte, Gewirtz.

\section{References}

AlSharari SD, Akbarali HI, Abdullah RA, Shahab O, Auttachoat W, Ferreira GA, White KL, Lichtman AH, Cabral GA, and Damaj MI (2013) Novel insights on the effect of nicotine in a murine colitis model. $J$ Pharmacol Exp Ther 344:207-217.

Al-Wadei HA, Al-Wadei MH, and Schuller HM (2012) Cooperative regulation of nonsmall cell lung carcinoma by nicotinic and beta-adrenergic receptors: a novel target for intervention. PLoS One 7:e29915.

Benowitz NL, Hukkanen J, and Jacob P, III (2009) Nicotine chemistry, metabolism, kinetics and biomarkers, in Nicotine Psychopharmacology (Henningfield JE, London ED, and Pogun S eds) pp 29-60, Springer, Heidelberg, Berlin.

Benowitz NL, Jacob P, III, and Savanapridi C (1987) Determinants of nicotine intake while chewing nicotine polacrilex gum. Clin Pharmacol Ther 41:467-473.

Brown KC, Perry HE, Lau JK, Jones DV, Pulliam JF, Thornhill BA, Crabtree CM, Luo H, Chen YC, and Dasgupta P (2013) Nicotine induces the up-regulation of the $\alpha 7$-nicotinic receptor ( $\alpha 7$-nAChR) in human squamous cell lung cancer cells via the Sp1/GATA protein pathway. J Biol Chem 288:33049-33059.

Carlisle DL, Liu X, Hopkins TM, Swick MC, Dhir R, and Siegfried JM (2007) Nicotine activates cell-signaling pathways through muscle-type and neuronal nicotinic acetylcholine receptors in non-small cell lung cancer cells. Pulm Pharmacol Ther 20:629-641.

Catassi A, Servent D, Paleari L, Cesario A, and Russo P (2008) Multiple roles of nicotine on cell proliferation and inhibition of apoptosis: implications on lung carcinogenesis. Mutat Res 659:221-231.

Chen GQ, Lin B, Dawson MI, and Zhang XK (2002) Nicotine modulates the effects of retinoids on growth inhibition and RAR $\beta$ expression in lung cancer cells. Int $J$ Cancer 99:171-178.

Chernyavsky AI, Shchepotin IB, Galitovkiy V, and Grando SA (2015) Mechanisms of tumor-promoting activities of nicotine in lung cancer: synergistic effects of cell membrane and mitochondrial nicotinic acetylcholine receptors. BMC Cancer 15: 152

Czyżykowski R, Połowinczak-Przybyłek J, and Potemski P (2016) Nicotine-induced resistance of non-small cell lung cancer to treatment-possible mechanisms. Postepy Hig Med Dosw 70:186-193.

Dang N, Meng X, and Song H (2016) Nicotinic acetylcholine receptors and cancer. Biomed Rep 4:515-518.

Dasgupta P, Kinkade R, Joshi B, Decook C, Haura E, and Chellappan S (2006) Nicotine inhibits apoptosis induced by chemotherapeutic drugs by up-regulating XIAP and survivin. Proc Natl Acad Sci USA 103:6332-6337.

Dasgupta P, Rizwani W, Pillai S, Davis R, Banerjee S, Hug K, Lloyd M, Coppola D, Haura E, and Chellappan SP (2011) ARRB1-mediated regulation of E2F target genes in nicotine-induced growth of lung tumors. $J$ Natl Cancer Inst 103:317-333.

Dasgupta P, Rizwani W, Pillai S, Kinkade R, Kovacs M, Rastogi S, Banerjee S, Carless M, Kim E, Coppola D, et al. (2009) Nicotine induces cell proliferation, invasion and epithelial-mesenchymal transition in a variety of human cancer cell lines. Int J Cancer 124:36-45.

Davis R, Rizwani W, Banerjee S, Kovacs M, Haura E, Coppola D, and Chellappan S (2009) Nicotine promotes tumor growth and metastasis in mouse models of lung cancer. PLoS One 4:e7524.

Di Cesare Mannelli L, Zanardelli M, and Ghelardini C (2013) Nicotine is a pain reliever in trauma- and chemotherapy-induced neuropathy models. Eur $J$ Pharmacol 711:87-94.

Egleton RD, Brown KC, and Dasgupta P (2008) Nicotinic acetylcholine receptors in cancer: multiple roles in proliferation and inhibition of apoptosis. Trends Pharmacol Sci 29:151-158.

Elgoyhen AB, Johnson DS, Boulter J, Vetter DE, and Heinemann S (1994) $\alpha 9$ : An acetylcholine receptor with novel pharmacological properties expressed in rat cochlear hair cells. Cell 79:705-715.

Fant RV, Henningfield JE, Shiffman S, Strahs KR, and Reitberg DP (2000) A pharmacokinetic crossover study to compare the absorption characteristics of three transdermal nicotine patches. Pharmacol Biochem Behav 67:479-482

Flood P and Daniel D (2004) Intranasal nicotine for postoperative pain treatment. Anesthesiology 101:1417-1421.

Gao T, Zhou X-L, Liu S, Rao C-X, Shi W, and Liu J-C (2016) In vitro effects of nicotine on the non-small-cell lung cancer line A549. J Pak Med Assoc 66:368-372.

Giacinti $\mathrm{C}$ and Giordano A (2006) RB and cell cycle progression. Oncogene 25: $5220-5227$.

Gong WYI, Wu JF, Liu BJ, Zhang HY, Cao YX, Sun J, Lv YB, Wu X, and Dong JC (2014) Flavonoid components in Scutellaria baicalensis inhibit nicotine-induced proliferation, metastasis and lung cancer-associated inflammation in vitro. Int $J$ Oncol 44:1561-1570.

Grando SA (2014) Connections of nicotine to cancer. Nat Rev Cancer 14:419-429.

Guo J, Kim D, Gao J, Kurtyka C, Chen H, Yu C, Wu D, Mittal A, Beg AA, Chellappan SP, et al. (2013) IKBKE is induced by STAT3 and tobacco carcinogen and determines chemosensitivity in non-small cell lung cancer. Oncogene 32:151-159.

Habib AS, White WD, El Gasim MA, Saleh G, Polascik TJ, Moul JW, and Gan TJ (2008) Transdermal nicotine for analgesia after radical retropubic prostatectomy. Anesth Analg 107:999-1004.

Haussmann H-J and Fariss MW (2016) Comprehensive review of epidemiological and animal studies on the potential carcinogenic effects of nicotine per se. Crit Rev Toxicol 46:701-734.

Heeschen C, Jang JJ, Weis M, Pathak A, Kaji S, Hu RS, Tsao PS, Johnson FL, and Cooke JP (2001) Nicotine stimulates angiogenesis and promotes tumor growth and atherosclerosis. Nat Med 7:833-839.
Huang L-C, Lin C-L, Qiu J-Z, Lin C-Y, Hsu K-W, Tam K-W, Lee J-Y, Yang J-M, and Lee C-H (2017) Nicotinic acetylcholine receptor subtype alpha-9 mediates triple-negative breast cancers based on a spontaneous pulmonary metastasis mouse model. Front Cell Neurosci 11:336.

Improgo MR, Soll LG, Tapper AR, and Gardner PD (2013) Nicotinic acetylcholine receptors mediate lung cancer growth. Front Physiol 4:251.

Improgo MR, Tapper AR, and Gardner PD (2011) Nicotinic acetylcholine receptormediated mechanisms in lung cancer. Biochem Pharmacol 82:1015-1021.

Iskandar AR, Liu C, Smith DE, Hu KQ, Choi SW, Ausman LM, and Wang XD (2013) $\beta$-Cryptoxanthin restores nicotine-reduced lung SIRT1 to normal levels and inhibits nicotine-promoted lung tumorigenesis and emphysema in A/J mice. Cancer Prev Res (Phila) 6:309-320.

Jarzynka MJ, Guo P, Bar-Joseph I, Hu B, and Cheng SY (2006) Estradiol and nicotine exposure enhances A549 bronchioloalveolar carcinoma xenograft growth in mice through the stimulation of angiogenesis. Int $J$ Oncol 28:337-344.

Jin Z, Gao F, Flagg T, and Deng X (2004) Nicotine induces multi-site phosphorylation of bad in association with suppression of apoptosis. J Biol Chem 279:23837-23844

Kyte SL, Toma W, Bagdas D, Meade JA, Schurman LD, Lichtman AH, Chen Z-J, Del Fabbro E, Fang X, Bigbee JW, et al. (2018) Nicotine prevents and reverses paclitaxel-induced mechanical allodynia in a mouse model of CIPN. J Pharmacol Exp Ther 364:110-119.

Lam DC, Girard L, Ramirez R, Chau WS, Suen WS, Sheridan S, Tin VP, Chung LP, Wong MP, Shay JW, et al. (2007) Expression of nicotinic acetylcholine receptor subunit genes in non-small-cell lung cancer reveals differences between smokers and nonsmokers. Cancer Res 67:4638-4647.

Li H, Wang S, Takayama K, Harada T, Okamoto I, Iwama E, Fujii A Ota K, Hidaka $\mathrm{N}$, Kawano Y, et al. (2015) Nicotine induces resistance to erlotinib via cross-talk between $\alpha 1$ nAChR and EGFR in the non-small cell lung cancer xenograft model. Lung Cancer 88:1-8.

Liu W, Yi DD, Guo JL, Xiang ZX, Deng LF, and He L (2015) Nuciferine, extracted from Nelumbo nucifera Gaertn, inhibits tumor-promoting effect of nicotine involving Wnt/ $\beta$-catenin signaling in non-small cell lung cancer. J Ethnopharmacol 165:83-93.

Ma X, Jia Y, Zu S, Li R, Jia Y, Zhao Y, Xiao D, Dang N, and Wang Y (2014) $\alpha 5$ Nicotinic acetylcholine receptor mediates nicotine-induced HIF-1 $\alpha$ and VEGF expression in non-small cell lung cancer. Toxicol Appl Pharmacol 278:172-179.

Maier CR, Hollander MC, Hobbs EA, Dogan I, Linnoila RI, and Dennis PA (2011) Nicotine does not enhance tumorigenesis in mutant K-ras-driven mouse models of lung cancer. Cancer Prev Res (Phila) 4:1743-1751.

Maneckjee R and Minna JD (1990) Opioid and nicotine receptors affect growth regulation of human lung cancer cell lines. Proc Natl Acad Sci USA 87:3294-3298.

Martínez-García E, Irigoyen M, González-Moreno O, Corrales L, Teijeira A, Salvo E, and Rouzaut A (2010) Repetitive nicotine exposure leads to a more malignant and metastasis-prone phenotype of SCLC: a molecular insight into the importance of quitting smoking during treatment. Toxicol Sci 116:467-476.

Matta SG, Balfour DJ, Benowitz NL, Boyd RT, Buccafusco JJ, Caggiula AR, Craig CR, Collins AC, Damaj MI, Donny EC, et al. (2007) Guidelines on nicotine dose selection for in vivo research. Psychopharmacology (Berl) 190:269-319.

Mucchietto V, Fasoli F, Pucci S, Moretti M, Benfante R, Maroli A, Di Lascio S, Bolchi C, Pallavicini M, Dowell C, et al. (2017) $\alpha 9$ - and $\alpha 7$-containing receptors mediate the pro-proliferative effects of nicotine in the A549 adenocarcinoma cell line. $B r$ J Pharmacol DOI: 10.1111/bph.13954 [published ahead of print].

Murphy SE, von Weymarn LB, Schutten MM, Kassie F, and Modiano JF (2011) Chronic nicotine consumption does not influence 4-(methylnitrosamino)1-(3-pyridyl)-1-butanone-induced lung tumorigenesis. Cancer Prev Res (Phila) 4:1752-1760.

Murray RP, Connett JE, and Zapawa LM (2009) Does nicotine replacement therapy cause cancer? Evidence from the Lung Health Study. Nicotine Tob Res 11: 1076-1082

Nair S, Bora-Singhal N, Perumal D, and Chellappan S (2014) Nicotine-mediated invasion and migration of non-small cell lung carcinoma cells by modulating STMN3 and GSPT1 genes in an ID1-dependent manner. Mol Cancer 13:173.

Nakada T, Kiyotani K, Iwano S, Uno T, Yokohira M, Yamakawa K, Fujieda M, Saito T, Yamazaki H, Imaida K, et al. (2012) Lung tumorigenesis promoted by antiapoptotic effects of cotinine, a nicotine metabolite through activation of PI3K/Akt pathway. J Toxicol Sci 37:555-563.

Nishioka T, Guo J, Yamamoto D, Chen L, Huppi P, and Chen CY (2010) Nicotine, through upregulating pro-survival signaling, cooperates with NNK to promote transformation. J Cell Biochem 109:152-161.

Nishioka T, Luo L-Y, Shen L, He H, Mariyannis A, Dai W, and Chen C (2014) Nicotine increases the resistance of lung cancer cells to cisplatin through enhancing Bcl-2 stability. Br J Cancer 110:1785-1792.

Ogburn PL Jr, Hurt RD, Croghan IT, Schroeder DR, Ramin KD, Offord KP, and Moyer TP (1999) Nicotine patch use in pregnant smokers: nicotine and cotinine levels and fetal effects. Am $J$ Obstet Gynecol 181:736-743.

Pelissier-Rota MA, Pelosi L, Meresse P, and Jacquier-Sarlin MR (2015) Nicotineinduced cellular stresses and autophagy in human cancer colon cells: a supportive effect on cell homeostasis via up-regulation of Cox-2 and PGE(2) production. Int $J$ Biochem Cell Biol 65:239-256.

Pillai S, Rizwani W, Li X, Rawal B, Nair S, Schell MJ, Bepler G, Haura E, Coppola D and Chellappan S (2011) ID1 facilitates the growth and metastasis of non-small cell lung cancer in response to nicotinic acetylcholine receptor and epidermal growth factor receptor signaling. Mol Cell Biol 31:3052-3067.

Pillai S, Trevino J, Rawal B, Singh S, Kovacs M, Li X, Schell M, Haura E, Bepler G, and Chellappan S (2015) $\beta$-arrestin-1 mediates nicotine-induced metastasis through E2F1 target genes that modulate epithelial-mesenchymal transition. Cancer Res 75:1009-1020.

Pratesi G, Cervi S, Balsari A, Bondiolotti G, and Vicentini LM (1996) Effect of serotonin and nicotine on the growth of a human small cell lung cancer xenograft. Anticancer Res 16:3615-3619. 
Puliyappadamba VT, Cheriyan VT, Thulasidasan AKT, Bava SV, Vinod BS, Prabhu PR, Varghese R, Bevin A, Venugopal S, and Anto RJ (2010) Nicotine-induced survival signaling in lung cancer cells is dependent on their p53 status while its down-regulation by curcumin is independent. Mol Cancer 9:220.

Rosner M, Schipany K, and Hengstschläger M (2013) Merging high-quality biochemical fractionation with a refined flow cytometry approach to monitor nucleocytoplasmic protein expression throughout the unperturbed mammalian cell cycle. Nat Protoc 8:602-626.

Rowell PP, Hurst HE, Marlowe C, and Bennett BD (1983) Oral administration of nicotine: its uptake and distribution after chronic administration to mice. $J$ Pharmacol Methods 9:249-261.

Schaal C and Chellappan SP (2014) Nicotine-mediated cell proliferation and tumor progression in smoking-related cancers. Mol Cancer Res 12:14-23.

Seretny M, Currie GL, Sena ES, Ramnarine S, Grant R, MacLeod MR, Colvin LA and Fallon M (2014) Incidence, prevalence, and predictors of chemotherapyinduced peripheral neuropathy: a systematic review and meta-analysis. Pain $\mathbf{1 5 5}$ $2461-2470$.

Shi J, Liu F, Zhang W, Liu X, Lin B, and Tang X (2015) Epigallocatechin-3-gallate inhibits nicotine-induced migration and invasion by the suppression of angiogenesis and epithelial-mesenchymal transition in non-small cell lung cancer cells. Oncol Rep 33:2972-2980.

Sokolova E, Matteoni C, and Nistri A (2005) Desensitization of neuronal nicotinic receptors of human neuroblastoma SH-SY5Y cells during short or long exposure to nicotine. Br J Pharmacol 146:1087-1095.

Sun $\mathrm{H}$ and Ma X (2015) $\alpha 5$-nAChR modulates nicotine-induced cell migration and invasion in A549 lung cancer cells. Exp Toxicol Pathol 67:477-482.

Togashi Y, Hayashi H, Okamoto K, Fumita S, Terashima M, de Velasco MA, Sakai K Fujita Y, Tomida S, Nakagawa K, et al. (2015) Chronic nicotine exposure mediates resistance to EGFR-TKI in EGFR-mutated lung cancer via an EGFR signal. Lung Cancer 88:16-23.

Tsurutani J, Castillo SS, Brognard J, Granville CA, Zhang C, Gills JJ, Sayyah J, and Dennis PA (2005) Tobacco components stimulate Akt-dependent proliferation and NFkappaB-dependent survival in lung cancer cells. Carcinogenesis 26 $1182-1195$.
Wagener TL, Floyd EL, Stepanov I, Driskill LM, Frank SG, Meier E, Leavens EL, Tackett AP, Molina N, and Queimado L (2017) Have combustible cigarettes met their match? The nicotine delivery profiles and harmful constituent exposures of second-generation and third-generation electronic cigarette users. Tob Control 26 : e23-e28.

Warren GW, Romano MA, Kudrimoti MR, Randall ME, McGarry RC, Singh AK, and Rangnekar VM (2012) Nicotinic modulation of therapeutic response in vitro and in vivo. Int $J$ Cancer 131:2519-2527.

Wu SQ, Lv YE, Lin BH, Luo LM, Lv SL, Bi AH, and Jia YS (2013) Silencing of periostin inhibits nicotine-mediated tumor cell growth and epithelial-mesenchymal transition in lung cancer cells. Mol Med Rep 7:875-880.

Xin M and Deng X (2005) Nicotine inactivation of the proapoptotic function of Bax through phosphorylation. J Biol Chem 280:10781-10789.

Zeng F, Li YC, Chen G, Zhang YK, Wang YK, Zhou SQ, Ma LN, Zhou JH, Huang YY, Zhu WY, et al. (2012) Nicotine inhibits cisplatin-induced apoptosis in NCI-H446 cells. Med Oncol 29:364-373.

Zhang J, Kamdar O, Le W, Rosen GD, and Upadhyay D (2009) Nicotine induces resistance to chemotherapy by modulating mitochondrial signaling in lung cancer Am J Respir Cell Mol Biol 40:135-146.

Zhang Q, Tang X, Zhang Z-F, Velikina R, Shi S, and Le AD (2007) Nicotine induces hypoxia-inducible factor- $1 \alpha$ expression in human lung cancer cells via nicotinic acetylcholine receptor-mediated signaling pathways. Clin Cancer Res 13: 4686-4694

Zhao J, Xin M, Wang T, Zhang Y, and Deng X (2009) Nicotine enhances the antiapoptotic function of Mcl-1 through phosphorylation. Mol Cancer Res 7:1954-1961.

Zheng Y, Ritzenthaler JD, Roman J, and Han S (2007) Nicotine stimulates human lung cancer cell growth by inducing fibronectin expression. Am J Respir Cell Mol Biol 37:681-690.

Address correspondence to: S. Lauren Kyte, Virginia Commonwealth University, Massey Cancer Center, 401 College Street, Richmond, VA 23298. E-mail: kytesl@mymail.vcu.edu 